\title{
Preservação in vitro da batata com ácido acetilsalicílico e duas fontes de carboidrato(1)
}

\author{
Gerson Renan de Luces Fortes ${ }^{(2)}$ e Jonny Everson Scherwinski Pereira(3)
}

\begin{abstract}
Resumo - O objetivo deste trabalho foi avaliar o efeito de carboidratos e do ácido acetilsalicílico (AAS) na preservação in vitro da batata (Solanum tuberosum L.), cultivar Macaca. Brotações de 1,5 a 2,0 cm de comprimento foram transferidas para meio de MS, acrescido de mio-inositol (100 mg L $\left.^{-1}\right)$ e ágar $\left(6 \mathrm{~g} \mathrm{~L}^{-1}\right)$. Testaram-se duas fontes de carboidrato, sacarose e manitol $(87,6 \mathrm{mM})$, e cinco concentrações de AAS $\left(0,30,60,90\right.$ e $\left.120 \mathrm{mg} \mathrm{L}^{-1}\right)$. O delineamento foi em blocos casualizados com quatro repetições por tratamento e cada repetição formada por oito tubos de ensaio com uma brotação. O material foi mantido à temperatura de $25 \pm 2^{\circ} \mathrm{C}$, fotoperíodo de 16 horas e radiação de $19 \mu \mathrm{E} \mathrm{m}^{-2} \mathrm{~s}^{-1}$. O crescimento e o número de gemas nas hastes foram avaliados por três meses. Passados nove meses, a sobrevivência e o número de microtubérculos também foram avaliados. O uso de manitol, associado às concentrações a partir de $30 \mathrm{mg} \mathrm{L}^{-1}$ de AAS, proporcionou menor crescimento e formação de gemas nas hastes. No meio suplementado com sacarose, a sobrevivência e o número de microtubérculos foram maiores, independentemente das concentrações de AAS utilizadas, após nove meses de cultivo.
\end{abstract}

Termos para indexação: Solanum tuberosum, manitol, sacarose, micropropagação, conservação de germoplasma.

\section{In vitro storage of potato under acetyl salicylic acid and two carbohydrate sources}

\begin{abstract}
The aim of this work was to evaluate the effect of carbohydrates and acetyl salicylic acid (ASA) during the in vitro storage of potato (Solanum tuberosum L.), cultivar Macaca. Stems derived from in vitro cultures were cut into 1.5 to $2.0 \mathrm{~cm}$ segments and inoculated in a MS medium supplemented with myo-inositol $\left(100 \mathrm{mg} \mathrm{L}^{-1}\right)$ and agar $\left(6 \mathrm{~g} \mathrm{~L}^{-1}\right)$. Sucrose and mannitol $87.6 \mathrm{mM}$ and five ASA concentrations $\left(0,30,60,90\right.$ and $\left.120 \mathrm{mg} \mathrm{L}^{-1}\right)$ were tested. The stems were cultured on $10 \mathrm{~mL}$ medium in test tubes $(20 \times 150 \mathrm{~mm})$ and incubated in a growth chamber at $25 \pm 2^{\circ} \mathrm{C}, 16$ hour photoperiod and $19 \mu \mathrm{E} \mathrm{m}^{-2} \mathrm{~s}^{-1}$ radiation. The growth and the bud number formed in the stems for a period of three months were evaluated. Nine months later the survival percentage and the number of microtubers formed were also evaluated. It was observed that the mannitol, associated with $30 \mathrm{mg} \mathrm{L}^{-1}$ of ASA provided the smallest growth and bud formation after three months of storage. The survival and the microtubers amount were larger when the stems were maintained in the medium supplemented with sucrose, apart from the ASA concentration, after nine months of storage.
\end{abstract}

Index terms: Solanum tuberosum, mannitol, sucrose, micropropagation, germplasm conservation.

\section{Introdução}

A manutenção de coleções in vitro tem sido considerada como um método alternativo à conservação de germoplasma, especialmente para espécies

(1) Aceito para publicação em 9 de novembro de 2000.

(2) Embrapa-Centro de Pesquisa Agropecuária de Clima Temperado, Caixa Postal 403, CEP 96001-970 Pelotas, RS. E-mail: gerson@ cpact.embrapa.br

(3) Universidade Federal de Pelotas, Faculdade de Agronomia Eliseu Maciel, Caixa Postal 354, CEP 96001-970 Pelotas, RS. Bolsista da Capes. E-mail: jscherwi@ufpel.tche.br propagadas vegetativamente (Roca et al. , 1991). Com o objetivo de reduzir ou até suprimir o crescimento das células e tecidos, o processo de preservação in vitro apresenta diversas vantagens sobre o processo de conservação de germoplasma no campo, e dentre elas destacam-se: a necessidade de menor espaço para ocupação do material; manutenção de material vegetal livre de patógenos; disponibilidade de material para ser imediatamente propagado, além da redução dos custos financeiros, entre outros (Dorion et al., 1991). 
Entre as técnicas mais utilizadas para reduzir o crescimento in vitro e, desta forma, estender o intervalo entre os subcultivos, encontra-se a redução da temperatura de incubação e a aplicação de retardantes osmóticos e hormonais ao meio nutritivo (Conceição et al., 1998; Martin et al., 1998; Golmirzaie \& Toledo, 1999). O manitol apresenta um efeito retardante no crescimento e desenvolvimento de um grande número de espécies, e é utilizado com bastante freqüência na conservação in vitro. Normalmente, este carboidrato é adicionado ao meio, para reduzir-lhe o potencial hídrico. Assim, os cultivos são sujeitos a uma desaceleração no seu crescimento, devido a um estresse osmótico causado pela redução na absorção de água e nutrientes do meio. Além disso, quando este carboidrato é combinado a algum inibidor de crescimento, como o ácido acetilsalicílico (AAS), são obtidos resultados superiores (Bhat \& Chandel, 1993; Lopez-Delgado et al., 1998).

Este trabalho teve como objetivo verificar a influência do ácido acetilsalicílico (AAS) e dos carboidratos sacarose e manitol no crescimento de hastes de batata durante sua preservação in vitro.

\section{Material e Métodos}

O trabalho foi desenvolvido no Laboratório de Cultura de Tecidos da Embrapa-Centro de Pesquisa Agropecuária de Clima Temperado, Pelotas, RS. Microestacas de batata (Solanum tuberosum L.), cultivar Macaca, oriundas da multiplicação in vitro, com 1,5 a 2,0 cm de comprimento e com duas gemas axilares, foram transferidas para meio com sais e vitaminas de MS (Murashige \& Skoog, 1962), acrescido de mio-inositol $\left(100 \mathrm{mg} \mathrm{L}^{-1}\right)$ e ágar $\left(6 \mathrm{~g} \mathrm{~L}^{-1}\right)$. A este meio também adicionou-se sacarose e manitol, na concentração de 87,6 mM e cinco concentrações de AAS $(0,30$, $\left.60,90,120 \mathrm{mg} \mathrm{L}^{-1}\right)$. O pH dos meios de cultura foi ajustado para 5,8 $\pm 0,1$ antes da adição do agente solidificante e autoclavagem à temperatura de $121^{\circ} \mathrm{C}$ e 1,5 atmosfera de pressão por 15 minutos.

Após a transferência das microestacas para os tubos de ensaio, o material vegetal foi mantido em câmara de crescimento, à temperatura de $25 \pm 2^{\circ} \mathrm{C}$, fotoperíodo de 16 horas, e radiação de $19 \mu \mathrm{E} \mathrm{m}^{-2} \mathrm{~s}^{-1}$, em que se avaliou quinzenalmente o crescimento (relação entre o tamanho final e inicial) e o número de gemas formadas nas brotações por um período de três meses.

Utilizou-se o delineamento em blocos casualizados, com quatro repetições por tratamento. Cada repetição foi for- mada por oito unidades experimentais, cada uma constituída por uma brotação em tubo de ensaio contendo $10 \mathrm{~mL}$ de meio de cultura.

Passados nove meses do início do experimento, a porcentagem de sobrevivência das hastes e o número de microtubérculos formados também foram avaliados. Para avaliar a sobrevivência dos explantes, utilizou-se de cada unidade experimental um explante de $1 \mathrm{a} 2 \mathrm{~cm}$ de comprimento e duas gemas. Desta forma, cada tratamento foi repetido quatro vezes. Cada repetição foi formada por oito explantes, introduzidos em frascos com capacidade de $250 \mathrm{~mL}$ com $40 \mathrm{~mL}$ de meio, delineados em blocos casualizados. O meio de cultura utilizado nesta etapa foi formado pelos sais e vitaminas de MS, suplementado com $100 \mathrm{mg} \mathrm{L}^{-1}$ de mio-inositol, $30 \mathrm{~g} \mathrm{~L}^{-1}$ de sacarose e solidificado com $6 \mathrm{~g} \mathrm{~L}^{-1}$ de ágar.

Para a análise estatística dos dados, utilizou-se o programa SANEST (Zonta \& Machado, 1984).

\section{Resultados e Discussão}

A curva referente à porcentagem de crescimento das hastes mantidas em meio com manitol mostrou um efeito quadrático, nitidamente descendente, com o aumento nas concentrações de AAS, até um ponto mínimo atingido em $86,2 \mathrm{mg} \mathrm{L}^{-1}$ (ponto de máxima eficiência calculada), quando a menor porcentagem de crescimento das brotações chegou a 19\%, após três meses de conservação (Figura 1). Quando se usou sacarose, mesmo associada às concentrações mais elevadas de AAS, o crescimento das brotações mostrou-se superior aos resultados obtidos com o manitol. Entretanto, houve um nítido decréscimo na porcentagem de crescimento das brotações, cultivadas em meio com sacarose, com o aumento nas concentrações de AAS. Assim, o uso de sacarose e AAS, na concentração de $120 \mathrm{mg} \mathrm{L}^{-1}$, proporcionou um crescimento de $96 \%$ nas brotações. Na ausência de AAS, o meio com sacarose propiciou um crescimento, nas brotações, de $167 \%$, enquanto no meio com manitol o crescimento foi de $107 \%$, aos 90 dias de cultivo (Figura 1).

As hastes apresentaram maior comprimento quando mantidas em meio de cultura sem a presença de AAS. Porém, o meio acrescido de manitol sempre proporcionou um comprimento significativamente menor das brotações, em relação às brotações mantidas em meio de cultura com sacarose, independentemente da concentração de AAS utilizada (Figura 1). Sarkar \& 
Naik (1998) também verificaram que a adição de manitol ao meio causou menor crescimento das hastes, quando comparado com o meio onde foi utilizado somente a sacarose como carboidrato. Siddiqui et al. (1996) e Lopez-Delgado et al. (1998) também observaram que a simples adição de manitol ao meio de cultura proporcionou hastes de menor comprimento, com um tamanho médio em torno de $5 \mathrm{~cm}$, ao final de um período de seis meses de estudo.
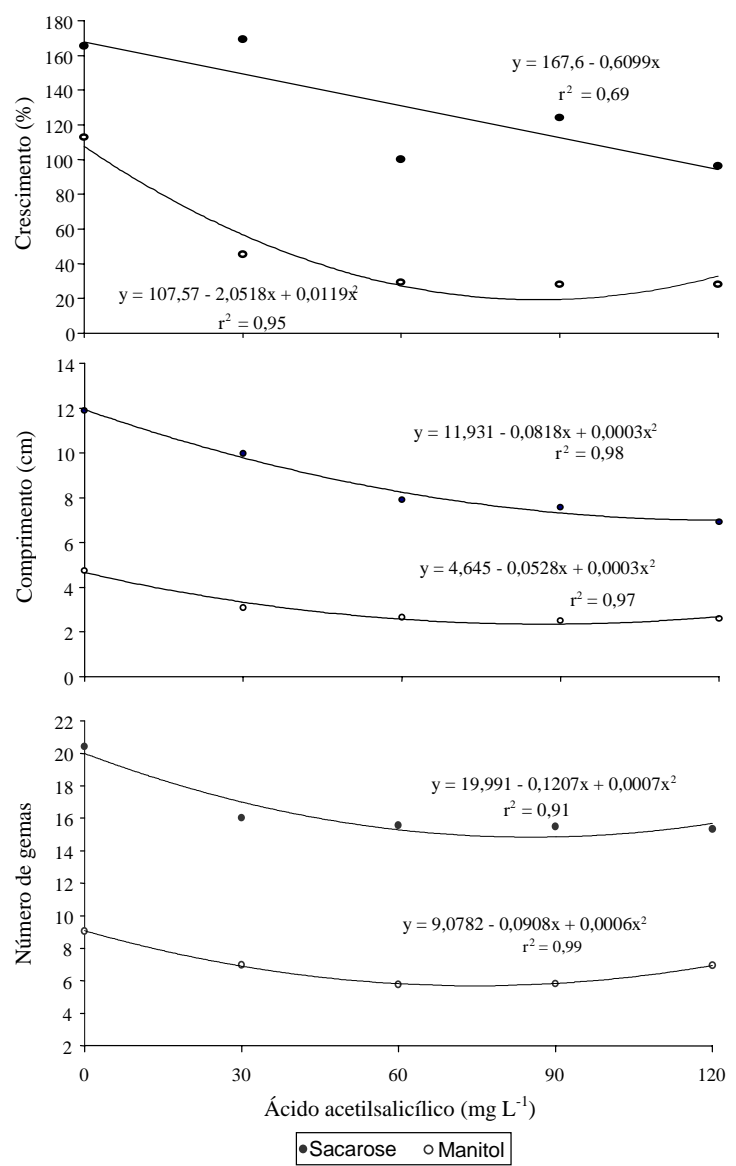

Figura 1. Porcentagem de crescimento, comprimento e número de gemas formadas (dados transformados em $\left.(y+0,5)^{1 / 2}\right)$ em hastes de batata em razão da fonte de carboidrato e de diferentes concentrações de ácido acetilsalicílico (AAS), após 90 dias de preservação in vitro. Pelotas, RS, 1999.
Houve nítida redução no comprimento das brotações com o aumento das concentrações de AAS quando se utilizou sacarose. Porém, em meio com manitol, esta redução foi mais pronunciada, observando-se que nas concentrações de 60,90 e $120 \mathrm{mg} \mathrm{L}^{-1}$ de AAS o comprimento médio das hastes foi de $2,5 \mathrm{~cm}$. Porém, para o meio de cultura contendo sacarose, o menor comprimento das brotações foi observado quando se utilizou o AAS na concentração mais elevada (120 $\left.\mathrm{mg} \mathrm{L}^{-1}\right)$. Neste caso, as hastes apresentaram comprimento médio de $7 \mathrm{~cm}$, ao final do período estudado (Figura 1).

Assim como observado quanto ao comprimento das hastes, o uso de manitol causou a formação de um número significativamente inferior de gemas nas brotações de batata, em comparação à sacarose. Quando associado ao AAS, foi o tratamento que proporcionou o menor número de gemas formadas com uma taxa de multiplicação em torno de 3:1 na concentração de $70 \mathrm{mg} \mathrm{L}^{-1}$ de AAS (calculado), após três meses de conservação. O maior número de gemas formadas foi observado quando não se acrescentou AAS ao meio de cultura em ambos os carboidratos testados, manitol e sacarose ( 9 e 20 gemas por brotação, respectivamente) (Figura 1).

A maior taxa de sobrevivência foi observada nos explantes provenientes do meio de cultura com sacarose, independentemente das concentrações de AAS utilizadas. Assim, 76\% dos explantes transferidos para a cultura e oriundos do meio suplementado com sacarose sobreviveram. Embora os tratamentos com manitol tenham reduzido mais efetivamente o crescimento das hastes, somente cerca de $37 \%$ dos explantes provenientes destes meios sobreviveram no período avaliado (Tabela 1). Esta evidência suge-

Tabela 1. Sobrevivência e número médio de microtubérculos formados em razão da fonte de carboidrato utilizada no meio de cultura, após nove meses de preservação in vitro da batata. Pelotas, RS, $1999^{(1)}$.

\begin{tabular}{ccc}
\hline Carboidrato & $\begin{array}{c}\text { Sobrevivência } \\
(\%)\end{array}$ & $\begin{array}{c}\text { Número de } \\
\text { microtubérculos/planta }\end{array}$ \\
\hline Sacarose & $76,00 \mathrm{a}$ & $3,46 \mathrm{a}$ \\
Manitol & $37,36 \mathrm{~b}$ & $0,04 \mathrm{~b}$ \\
\hline CV $(\%)$ & 51,00 & 32,40 \\
\hline
\end{tabular}

${ }^{(1)} \mathrm{Em}$ cada coluna, médias seguidas por letras distintas diferem entre si pelo teste de Duncan a $5 \%$ de probabilidade. 
re que as hastes de batata em presença de manitol sofrem maior estresse fisiológico que as crescidas em meio com sacarose, como tem sido descrito por outros autores, devido, principalmente, ao estresse osmótico provocado por esse carboidrato ao meio de cultura, que reduz a absorção de água e nutrientes pelos cultivos (Bhat \& Chandel, 1993; LopezDelgado et al., 1998).

Após nove meses de preservação in vitro, constatou-se a formação de microtubérculos nos meios de cultura suplementados com sacarose em número significativamente superior ao dos tratamentos onde se utilizou o manitol como fonte de carboidrato (Tabela 1). Contudo, a formação de microtubérculos não foi influenciada pelas concentrações de AAS no meio de cultura. Koda et al. (1992) também observaram maior formação de microtubérculos em meio de cultura com sacarose, mesmo na presença de AAS.

\section{Conclusões}

1. O uso de manitol proporciona menor crescimento e número de gemas formadas em hastes de batata in vitro.

2. O crescimento das hastes de batata é retardado com a adição de AAS ao meio de cultura associado com o manitol, a partir da concentração de $30 \mathrm{mg} \mathrm{L}^{-1}$.

3. A sobrevivência das hastes conservadas em meio suplementado com sacarose é maior do que as conservadas em meio de cultura com manitol.

4. O meio suplementado com sacarose leva à formação de microtubérculos após nove meses de preservação in vitro da batata.

\section{Referências}

BHAT, S. R.; CHANDEL, K. P. S. In vitro conservation of Musa germplasm: effects of mannitol and temperature on growth and storage. Journal of Horticultural Science, Ashford, v. 68, n. 6, p. 841-846, 1993.

CONCEIÇÃO, A. M. da; FORTES, G. R. de L.; SILVA, J. B. da. Conservação in vitro de batata (Solanum tuberosum) cvs. Baronesa e Santo Amor: efeito sobre a formação de gemas e brotações dos segmentos caulinares.
Agropecuária de Clima Temperado, Pelotas, v. 1, n. 1, p. 67-71, 1998.

DORION, N.; KADRI, M.; BIGOT, C. In vitro preservation at low temperature of rose plantlets usable for direct acclimatization. Acta Horticulturae, Leuven, v. 298, p. 335-343, 1991.

GOLMIRZAIE, A.; TOLEDO, J. In vitro conservation of potato and sweet potato germplasm. In: ARTHUR, C.; FERGUNSON, P.; SMITH, B. (Ed.). Impact on a changing world: program report 1997-1998. Lima: International Potato Center, 1999. p. 351-356.

KODA, Y.; TAKAHASHI, K.; KIKUTA, Y. Potato tuberinducing activities of salicylic acid and related compounds. Journal of Plant Growth Regulation, Berlin, v. 11, p. 215-219, 1992.

LOPES-DELGADO, H.; JIMENEZ-CASAS, M.; SCOTT, I. M. Storage of potato microplants in vitro in the presence of acetyl salicylic acid. Plant Cell, Tissue and Organ Culture, Dordrecht, v. 54, n. 3, p. 145-152, 1998.

MARTIN, C.; IRIONDO, J. M.; GONZALES-BENITO, E.; PEREZ, C. The use of tissue culture techniques in the conservation of plant biodiversity. Agro Food Industry Hi-Tech, Milan, v. 9, n. 1, p. 37-40, 1998.

MURASHIGE, T.; SKOOG, F. A revised medium for rapid growth and bioessays with tobacco tissue cultures. Physiology Plantarum, Copenhagen, v. 15, p. 473-479, 1962.

ROCA, W. M.; ARIAS, D. I.; CHAVES, R. Métodos de conservación in vitro del germoplasma. In: ROCA, W. M.; MROGINSKI, L. A. (Ed.). Cultivo de tejidos en la agricultura: fundamentos y aplicaciones. Cali: Centro Internacional de Agricultura Tropical, 1991. p. 697-714.

SARKAR, D.; NAIK, P. S. Factors affecting minimal growth conservation of potato microplants in vitro. Euphytica, Dordrecht, v. 102, n. 2, p. 275-280, 1998.

SIDDIQUI, S. U.; CHAUDHARY, M. F.; ANWAR, R. Studies in the in vitro conservation of potato (Solanum tuberosum L.) germplasm in Pakistan. Plant Genetic Resources Newsletter, Rome, v. 107, p. 28-30, 1996.

ZONTA, E. P.; MACHADO, A. A. SANEST: sistema de análise estatística para microcomputadores. Pelotas: UFPel, 1984. 138 p. 